\title{
RESEARCH
}

Open Access

\section{Direct comparison of magnetic resonance imaging and pathological shrinkage patterns of triple-negative breast cancer after neoadjuvant chemotherapy}

Katsuhiro Yoshikawa ${ }^{1,2}$, Mitsuaki Ishida ${ }^{1 *}$, Naoki Kan ${ }^{3}$, Hirotsugu Yanai ${ }^{2}$, Koji Tsuta $^{1}$, Mitsugu Sekimoto ${ }^{2}$ and Tomoharu Sugie ${ }^{2}$

\begin{abstract}
Background: We aimed to investigate the usefulness of magnetic resonance imaging (MRI) and histopathological shrinkage patterns to formulate a predictive equation for estimating residual tumor size after neoadjuvant chemotherapy (NAC) in triple-negative breast cancer (TNBC) patients.

Methods: We enrolled 34 TNBC patients who underwent MRI before and after NAC. The MRI and histopathological shrinkage patterns were analyzed and classified into five categories-types I and II (concentric shrinkage without or with surrounding lesions, respectively), type III (shrinkage with residual multinodular lesions), type IV (diffuse contrast enhancement in the entire quadrant), and non-visualization. The residual tumor sizes following MRI and histopathological examination were also compared.

Results: The most common MRI and histopathological shrinkage pattern was type I (41.2\% and 38.2\%, respectively), followed by non-visualization ( $26.5 \%$ and $32.4 \%$, respectively); the concordance rate between MRI and histopathological shrinkage patterns was $41.2 \%$. There was a strong correlation between MRI tumor size and pathological tumor size $(r=0.89)$. Based on these findings, a predictive equation for pathological tumor size was formulated as follows: pathological tumor size $(\mathrm{mm})=1.1502 \times($ MRl tumor size $[\mathrm{mm}])+8.4277$.
\end{abstract}

Conclusions: Our equation may aid accurate preoperative assessment. Further studies are needed to determine its predictive value and applicability.

Keywords: Triple-negative breast cancer, Magnetic resonance imaging, Neoadjuvant chemotherapy, Residual tumor diameter, Predictive equation

\footnotetext{
* Correspondence: ishidamt@hirakata.kmu.ac.jp

'Department of Pathology and Clinical Laboratory, Kansai Medical University,

2-5-1, Shinmachi, Hirakata City, Osaka Prefecture 573-1010, Japan

Full list of author information is available at the end of the article
}

(c) The Author(s). 2020 Open Access This article is licensed under a Creative Commons Attribution 4.0 International License, which permits use, sharing, adaptation, distribution and reproduction in any medium or format, as long as you give appropriate credit to the original author(s) and the source, provide a link to the Creative Commons licence, and indicate if changes were made. The images or other third party material in this article are included in the article's Creative Commons licence, unless indicated otherwise in a credit line to the material. If material is not included in the article's Creative Commons licence and your intended use is not permitted by statutory regulation or exceeds the permitted use, you will need to obtain permission directly from the copyright holder. To view a copy of this licence, visit http://creativecommons.org/licenses/by/4.0/ The Creative Commons Public Domain Dedication waiver (http://creativecommons.org/publicdomain/zero/1.0/) applies to the data made available in this article, unless otherwise stated in a credit line to the data. 


\section{Background}

Triple-negative breast cancer (TNBC), defined by a lack of estrogen receptor, progesterone receptor, and human epidermal growth factor receptor 2 (HER2) expression, is a high-grade phenotype of breast cancer with a poor prognosis $[1,2]$. Although TNBC represents $12-17 \%$ of breast cancer patients, it is well-known that the rates of recurrence and/or distant metastasis, as well as mortality, are significantly higher in TNBC than other breast cancer subtypes [3]. Patients with TNBC therefore often require adjuvant chemotherapy. Several large randomized clinical trials have demonstrated equivalent efficacy between neoadjuvant chemotherapy (NAC) and adjuvant chemotherapy and suggest that NAC improves the success rate of breast-conserving surgery (BCS) [4-9]. Therefore, NAC is particularly recommended for patients with TNBC who are intended to receive BCS [10]. However, because patients undergoing NAC have higher local recurrence rates, the extent of resection must be carefully determined [11].

Magnetic resonance imaging (MRI) is widely used and plays a pivotal role in guiding the extent of breast surgery by providing estimates of the tumor size and distribution after NAC $[12,13]$. The superiority of MRI over ultrasound and mammography is well-recognized [14]. Obtaining accurate imaging information on the extent and distribution of residual carcinoma after NAC is of utmost importance, as over-estimation of the residual tumor size may lead to unnecessary mastectomies. Conversely, under-estimation may result in tumors on ink followed by additional surgeries. Despite this, there are very few reports comparing MRI and histopathology in terms of shrinkage patterns and tumor size. Our study intended to analyze the detailed radiopathological correlation between MRI patterns before and after NAC and pathological tumor residual patterns in patients with TNBC. The tumor diameter after NAC was also evaluated using MRI, and a predictive equation was developed to estimate the residual tumor diameter based on these findings.

\section{Methods}

\section{Patient selection}

We enrolled 165 consecutive patients with TNBC who underwent surgical resection at the Department of Surgery of the Kansai Medical University Hospital between January 2006 and December 2018. Patients who did not receive NAC or did not undergo MRI before and after NAC were excluded from the study; finally, 34 patients with TNBC were included.

This study was conducted in accordance with the principles of the Declaration of Helsinki, and the study protocol was approved by the Institutional Review Board of the Kansai Medical University Hospital (protocol no.
2019041). Informed consent was individually obtained from all participants included in the study.

\section{Chemotherapy}

The NAC regimens were selected based on patients' preferences. Overall, 33 (97\%) patients received sequential anthracycline- and taxane-based regimens. The anthracycline-based regimens included EC (epirubicin $100 \mathrm{mg} / \mathrm{m}^{2}$ and cyclophosphamide $500 \mathrm{mg} / \mathrm{m}^{2}$ ), AC (doxorubicin $60 \mathrm{mg} / \mathrm{m}^{2}$ and cyclophosphamide $600 \mathrm{mg} / \mathrm{m}^{2}$ ), and FEC (epirubicin $100 \mathrm{mg} / \mathrm{m}^{2}$, cyclophosphamide $500 \mathrm{mg} / \mathrm{m}^{2}$, and 5-fluorouracil $500 \mathrm{mg} /$ $\mathrm{m}^{2}$ ). Chemotherapy was administered every 3 weeks for $4 \mathrm{cy}$ cles. The taxane-based regimens included docetaxel at a dose of $70 \mathrm{mg} / \mathrm{m}^{2}$ every 3 weeks for 4 cycles, or weekly paclitaxel at a dose of $80 \mathrm{mg} / \mathrm{m}^{2}$ for 12 doses with scheduled rests. Only one patient received a taxane-based regimen without anthracyclines (docetaxel $75 \mathrm{mg} / \mathrm{m}^{2}$ and cyclophosphamide $600 \mathrm{mg} / \mathrm{m}^{2}$ ).

\section{MRI technique}

MRI was performed using 1.5-T scanners (Signa Excite HD; GE Healthcare, Milwaukee, WI, USA) with a dedicated breast coil. All images were obtained in the prone position. All patients received intravenous contrast (0.1 $\mathrm{mmol} / \mathrm{kg}$ gadopentetate dimeglumine).

MRI was performed 2 to 4 weeks prior to and following completion of NAC.

\section{Interpretation of MRI}

Two experienced breast surgeons and one experienced breast-imaging radiologist conjointly reviewed the preand post-NAC breast MRI findings of all patients.

The contrast-enhanced MRI patterns prior to NAC were classified into five categories, as described by Tomida et al. [15] —solitary, grouped (localized lesion with linear and/or spotty enhancement), separated (multiple foci of contrast enhancement), mixed (grouped lesion with multiple foci), and replaced (diffuse contrast enhancement in entire quadrant) lesions. The MRI shrinkage patterns of breast cancer following NAC were classified into five categories, as suggested by Kim et al. [16]-type I (concentric shrinkage without any surrounding lesion), type II (concentric shrinkage with surrounding lesions), type III (shrinkage with residual multi-nodular lesions), type IV (diffuse contrast enhancement in entire quadrant), and non-visualization. Breast cancer reactions after NAC were determined using the response evaluation criteria in solid tumor classification [17], based on unidimensional measurements of the largest tumor diameter.

\section{Histopathological examination}

The histopathological diagnosis of the breast cancers was independently performed by two experienced 
diagnostic pathologists. The response following NAC was assessed based on the Miller-Payne grading system, established by Ogston et al. [18]. The grades are as follows: grade 1 , no change or particular alteration to individual malignant cells and no reduction in overall cellularity; grade 2 , minor loss of tumor cells $(\leq 30 \%)$ with overall cellularity remaining high; grade 3 , an estimated 30 to $90 \%$ reduction in tumor cells; grade 4 , a marked disappearance of tumor cells so that only small clusters or widely dispersed individual cells remain, with $>90 \%$ loss of tumor cells; and grade 5, no malignant cells identified in sections from the tumor site, only vascular fibroelastic stroma remaining, often containing macrophages, with possible presence of intraductal carcinoma components.

The histopathological patterns of the residual tumor were also classified into five categories, similar to the classification of MRI shrinkage patterns [15]. Histopathological tumor size was determined based on unidimensional measurements of the largest tumor diameter (including ductal component). A free margin of $2 \mathrm{~mm}$ or less was defined as positive [19].

\section{Statistical analysis}

All analyses were performed using the SPSS Statistics 25.0 software (IBM, Armonk, NY, USA). Agreement between two groups was analyzed using the Kappa test.

The Pearson correlation coefficient was used to compare tumor size on MRI with the histological tumor size. A $P$ value of less than 0.05 was regarded as significant. Moreover, a predictive equation for the pathological tumor size based on MRI findings was evaluated using the least square method.

\section{Results}

\section{Patients' characteristics}

The characteristics of patients in the present cohort are summarized in Table 1 . This study included 34 patients; all were female. The median age at the time of initial diagnosis was 53 (range 31-77) years. All patients were diagnosed with TNBC based on the biopsy specimens; 31,2 , and 1 patients were diagnosed with invasive carcinoma of no special type, apocrine carcinoma, and invasive lobular carcinoma, respectively. Ten patients were initially diagnosed with clinical stage I, 10 with stage IIA, 9 with stage IIB, 2 with stage IIIA, 1 with stage IIIB, and 2 with stage IIIC, respectively, according to the 8th Union for International Cancer Control TNM Classification [20].

\section{MRI findings before and after NAC}

The most common enhancement pattern before NAC was solitary (20 patients, $58.8 \%$ ), followed in order by separated (7 patients, 20.6\%), grouped (5 patients, 14.7\%), and replaced
Table 1 Clinical characteristics of patients with triple negative breast cancer

\begin{tabular}{|c|c|c|c|}
\hline Factor & Median (range) & $n$ & $\%$ \\
\hline Total & & 34 & \\
\hline Age (years) & $53(31-77)$ & & \\
\hline \multirow[t]{3}{*}{ Menopausal status } & Premenopausal & 11 & 32.4 \\
\hline & Postmenopausal & 20 & 58.8 \\
\hline & Unknown & 3 & 8.8 \\
\hline \multirow[t]{3}{*}{ Histology } & $\begin{array}{l}\text { Invasive carcinoma, no } \\
\text { special type }\end{array}$ & 31 & 91.2 \\
\hline & Invasive lobular carcinoma & 1 & 2.9 \\
\hline & Apocrine carcinoma & 2 & 5.9 \\
\hline \multirow[t]{6}{*}{ Initial clinical stage } & 1 & 10 & 29.4 \\
\hline & $\| \mathrm{A}$ & 10 & 29.4 \\
\hline & $\| \mathrm{B}$ & 9 & 26.5 \\
\hline & $\| \mathrm{A}$ & 2 & 5.9 \\
\hline & $\| \mathrm{IIB}$ & 1 & 2.9 \\
\hline & $\| I C$ & 2 & 5.9 \\
\hline \multirow[t]{3}{*}{ Ki-67 } & Low $(\leq 20 \%)$ & 2 & 5.9 \\
\hline & High (> 20\%) & 29 & 85.3 \\
\hline & Unknown & 3 & 8.8 \\
\hline \multirow[t]{2}{*}{ Lymph node metastasis } & Present & 15 & 44.1 \\
\hline & Absent & 19 & 55.9 \\
\hline \multirow{2}{*}{$\begin{array}{l}\text { Neoadjuvant chemotherapy } \\
\text { regimen }\end{array}$} & Taxane & 1 & 2.9 \\
\hline & Taxane + anthracycline & 33 & 97.1 \\
\hline \multirow[t]{2}{*}{ Type of surgery } & Radical mastectomy & 11 & 32.4 \\
\hline & Partial mastectomy & 23 & 67.6 \\
\hline
\end{tabular}

(2 patients, 5.9\%) lesions (Fig. 1a-d; Table 2). None of the patients in the present study showed mixed enhancement patterns.

Table 2 summarizes the tumor shrinkage patterns after NAC. The most common shrinkage pattern on MRI was type I (14 patients, $41.2 \%)$, followed in order by non-visualization (9 patients, $26.5 \%)$, type III (5 patients, $14.7 \%$ ), type II (4 patients, $11.8 \%$ ), and type IV (2 patients, $5.9 \%$ ) (Fig. $2 \mathrm{a}-\mathrm{e}$; Table 2). For the association between the initial findings and shrinkage patterns in MRI, the most common shrinkage pattern (type I) was observed in $60 \%$ of the patients with solitary patterns, followed by non-visualization, which was observed in $30 \%$ (Table 2). Patients with non-visualization patterns after NAC initially had either solitary or separated enhancement patterns. MRI shrinkage patterns did not significantly correlate with the clinicopathological parameters, including the menopausal status, clinical stage of the tumor, and Ki-67 labeling index.

\section{Histopathological features following NAC}

The most common histopathological regression grade was 1 (12 patients, 35.3\%), followed by grades 5 (11 


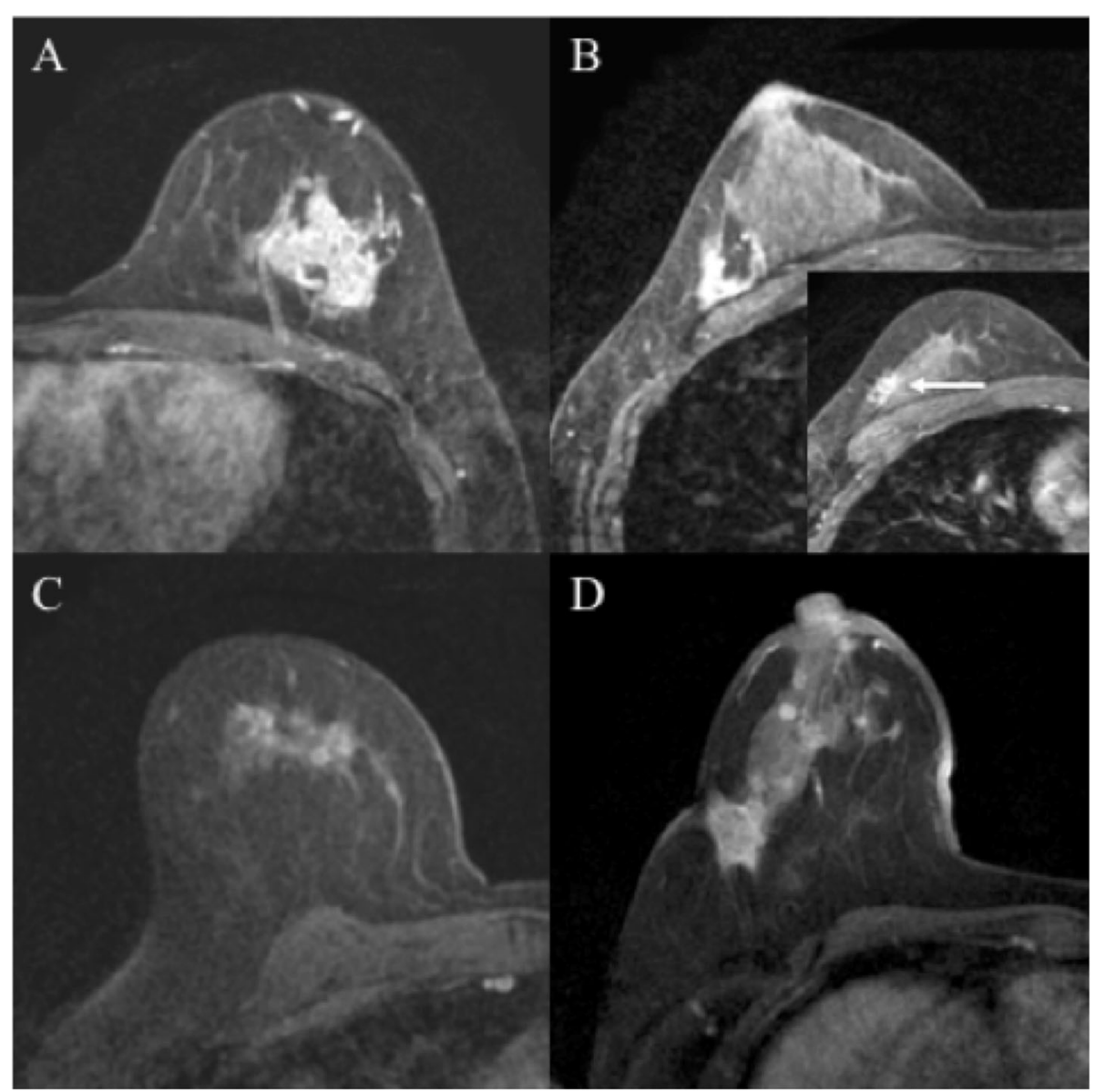

Fig. 1 Magnetic resonance images of the initial enhancement patterns of triple-negative breast cancer prior to neoadjuvant chemotherapy. a Solitary, b separated (arrow shows the daughter nodule), c grouped, and $\mathbf{d}$ replaced

patients, 32.4\%), 2 (6 patients, 17.6\%), 4 (4 patients, $11.8 \%$ ), and 3 (1 patient, $2.9 \%$ ) (Fig. 3a-d; Table 3). The most common shrinkage pattern on histopathology was type I, observed in $38.2 \%$ of the patients, followed in order by non-visualization (32.1\%), type III (20.6\%), type II (5.9\%), and type IV (2.9\%) (Table 3). The observed concordance between the shrinkage patterns on MRI and on histopathology was $41.2 \%$ (Kappa statistics 0.181,

Table 2 Correlation between initial contrast-enhancement patterns prior to neoadjuvant chemotherapy and shrinkage patterns

\begin{tabular}{lllll}
\hline Shrinkage & \multicolumn{4}{l}{ Initial enhancement patterns } \\
\cline { 2 - 5 } patterns & Solitary & Grouped & Separated & Replaced \\
\hline Non-visualization & 6 & 0 & 3 & 0 \\
Type I & 12 & 1 & 1 & 0 \\
Type II & 1 & 2 & 1 & 0 \\
Type III & 1 & 2 & 2 & 0 \\
Type IV & 0 & 0 & 0 & 2 \\
\hline
\end{tabular}

$p=0.07)$. Subsequently, we performed a direct comparison between MRI-based and histopathological shrinkage patterns in TNBC. Among 11 patients with no residual disease, six were diagnosed as having non-visualization pattern on MRI (sensitivity, 54.5\%). In the other five patients, type I MRI shrinkage pattern was observed in 1 patient, type II in 2, and type III in 2 other patients (Table 3). Among the 23 patients who had residual disease, three did not show contrast-enhanced lesions on MRI (specificity 87.0\%). Pathological shrinkage patterns did not significantly correlate with the clinicopathological parameters, including the menopausal status, clinical stage of the tumor, and Ki-67 labeling index.

\section{Relationship between MRI and histopathological tumor sizes after NAC}

Next, we assessed the residual tumor size on MRI and on histopathology after NAC in 25 patients with TNBC. There was a significant correlation between MRI tumor size and histopathological tumor size (Pearson's correlation coefficient of $0.89, p<0.0001$ ) (Fig. 4). The mean 


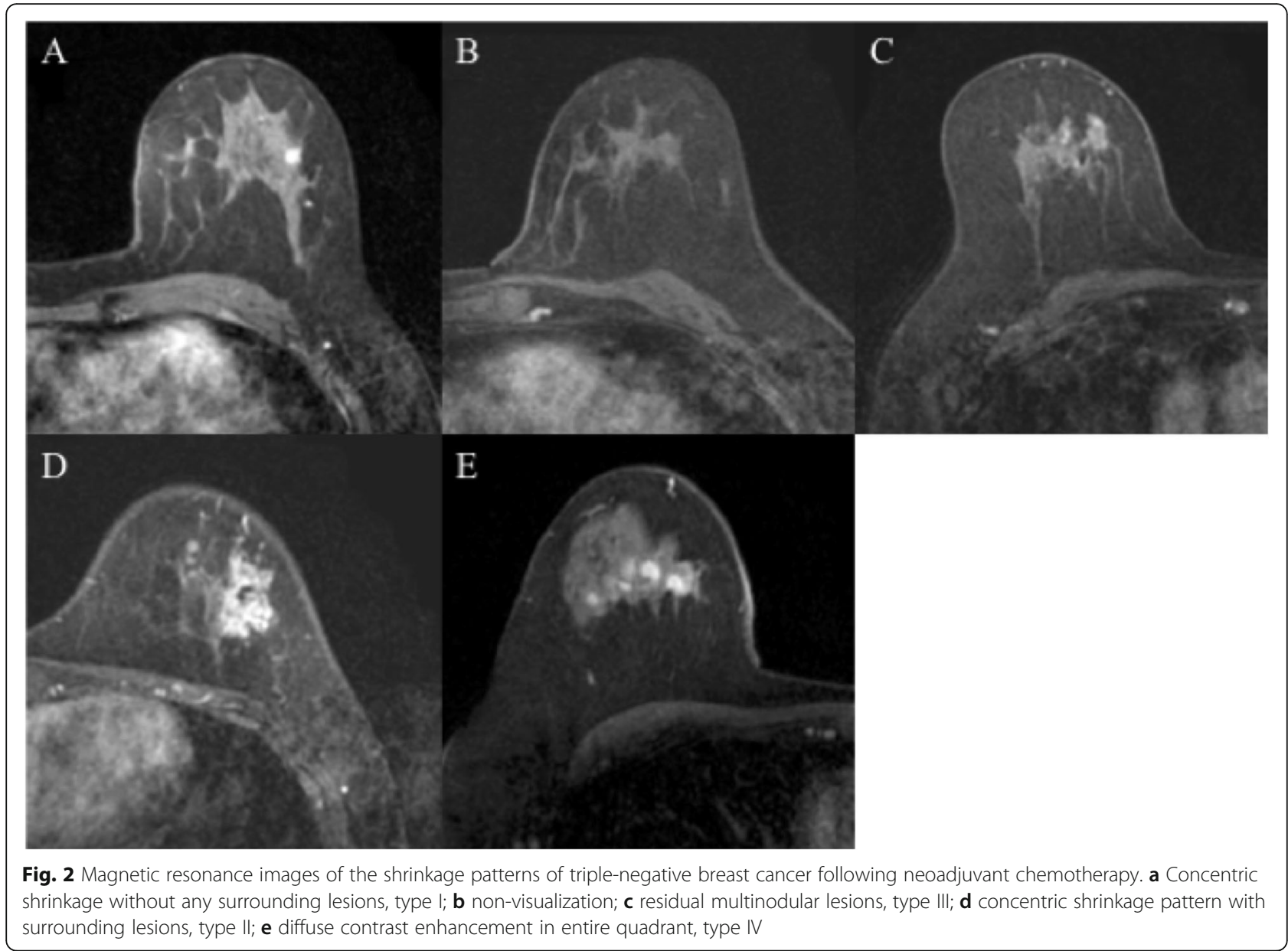

difference between MRI-based and histopathology-based tumor diameter was $11.5 \pm 12.7 \mathrm{~mm}$. The following equation was developed based on the findings:

$$
\begin{aligned}
& \text { Pathological residual tumor size }(\mathrm{mm}) \\
& \quad=1.1502 \times(\text { residual tumor size }[\mathrm{mm}])+8.4277
\end{aligned}
$$

This equation can be applied to patients with MRI shrinkage patterns that are reflective of types I, II, III, and IV (excluding non-visualization). "Pathological residual tumor size" implies the total tumor size including invasive carcinoma and intraductal carcinoma components. If a resection size was estimated based on this equation before surgery, a safe margin of $10 \mathrm{~mm}$ beyond the calculated pathological size would lead to a positive margin rate of $4 \%$. Moreover, a $20-\mathrm{mm}$ safe margin would result in a positive margin rate of $0 \%$.

\section{Discussion}

In the present study, we demonstrated a significant correlation between MRI and histopathology for residual tumor size and obtained a predictive equation to estimate the size of residual tumors using MRI results. Furthermore, the correlation between MRI and histopathological shrinkage patterns in patients with TNBC after NAC was relatively high.

Several reports have elucidated the shrinkage patterns of breast cancer after NAC. Kim et al. studied the shrinkage tumor patterns on MRI following NAC, and they reported that the most common MRI shrinkage patterns in breast cancer patients were type I (51.8\%), followed by type II (23.2\%) [16]. Tomida et al. studied the correlation between MRI shrinkage patterns and pathological shrinkage patterns following NAC. They reported that the most common pathological shrinkage pattern was type II (40.7\%), followed by type III (29.6\%), and the concordance rate between MRI and histopathological patterns was 48\% [15]. However, these two studies did not examine the relationship between the shrinkage patterns of various molecular subtypes of breast cancer. In the present study, the high rate of type I (41.2\%), the relatively high rate of non-visualization (26.5\%), and the low rate of type II (11.8\%) patterns may be a characteristic feature of MRI shrinkage patterns in TNBC. Furthermore, the present study found that high 


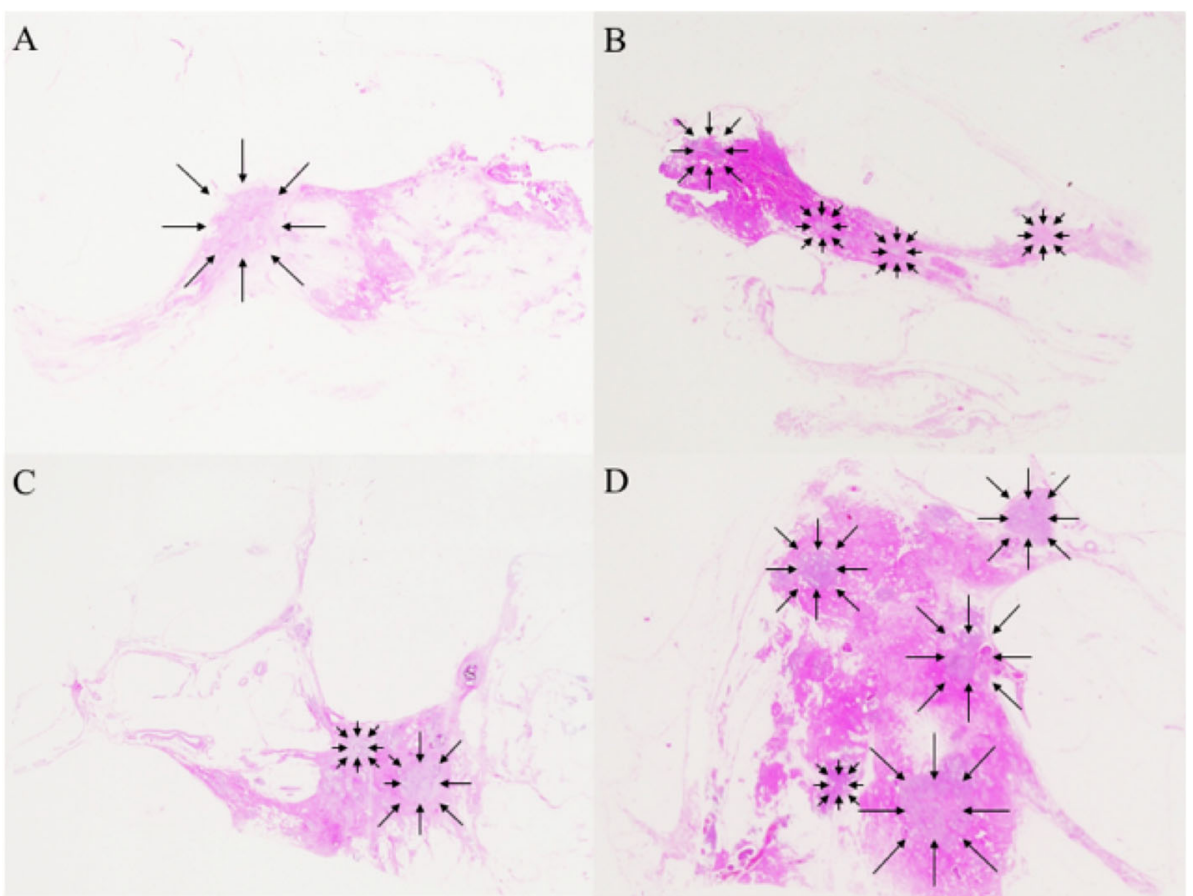

Fig. 3 Panoramic view of the histopathological shrinkage patterns and features following neoadjuvant chemotherapy. a Pathological type I showing concentric shrinkage without any surrounding lesions. b Pathological type III demonstrating shrinkage with residual multinodular lesions. c Pathological type II showing concentric shrinkage with surrounding lesions. $\mathbf{d}$ Pathological type IV demonstrating multiple residual carcinomas (arrows: residual carcinoma cells); hematoxylin and eosin staining

frequencies of type I (38.2\%) and non-visualization (32.4\%) pathological shrinkage patterns were characteristic of TNBC. The concordance rate of $41.2 \%$ between MRI and pathological shrinkage patterns in the present cohort was comparable to that of the previous report (48\%), in which no distinction among molecular subtypes was found [15].

Because of the high effectiveness of chemotherapy observed in patients with TNBC [21], our study resulted in a high frequency of the "non-visualization" pathological pattern, compared to previous reports $[15,16]$.

Table 3 Correlation between MRI shrinkage patterns and pathological shrinkage patterns following neoadjuvant chemotherapy

\begin{tabular}{llllll}
\hline \multicolumn{5}{c}{ Pathological shrinkage pattern } \\
\cline { 2 - 6 } & Non-visualization & Type I & Type II & Type III & Type IV \\
\hline MRI shrinkage pattern & 2 & 0 & 1 & 0 \\
Non-visualization & 6 & 8 & 1 & 3 & 1 \\
Type I & 1 & 0 & 0 & 2 & 0 \\
Type II & 2 & 2 & 1 & 0 & 0 \\
Type III & 2 & 1 & 0 & 1 & 0 \\
Type IV & 0 & & &
\end{tabular}

Moreover, the high frequency of type I pathological shrinkage pattern suggests that the concentric shrinkage pattern may be more commonly found in TNBC than in other molecular subtypes after NAC. These characteristics of TNBC may be attributed to differences in the efficacy of NAC, evidenced by the variation observed in the tumor shrinkage patterns after NAC among different molecular subtypes.

MRI is known to be useful for predicting pathological complete responses (pCR) after NAC. Liu et al. reported a high specificity (88\%) and relatively low sensitivity (65\%) for MRI in predicting pCR among patients with breast cancer [22]. Although the molecular subtypes were not classified in their reports, the results of the present study concur with theirs. Therefore, TNBC may have a similar tendency to other molecular subtypes on pCR prediction.

Nakahara et al. reported that TNBC showed a significant correlation between the residual tumor sizes obtained on MRI and pathological tumor sizes after NAC [23]. However, an MRI-based predictive equation for residual tumor size has yet to be developed. The development of an accurate MRI-based measurement tool is of particular necessity for patients receiving NAC and BCS, a matter that needs to be urgently addressed. Our predictive equation may help to estimate accurately tumor 


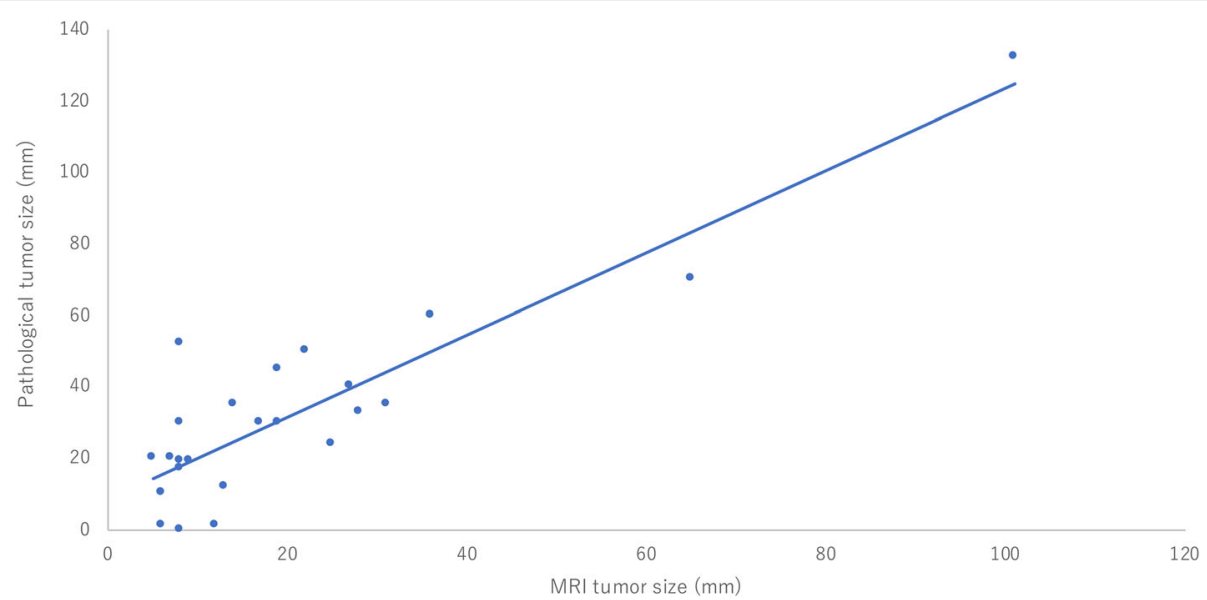

Fig. 4 Correlation between MRI and pathological tumor sizes in patients with non-clinical complete remission. Correlation coefficient $(r)=0.89(p$ $<0.0001$ )

size and to reduce the high rate $(2-40 \%)$ of tumors on ink reported in patients undergoing BCS after NAC [24].

The present study had several limitations. First, it was a retrospective single-institution study with a small sample size, and therefore, selection bias was a possibility. Second, the present study only analyzed TNBC. Since the MRI and pathological shrinkage patterns after NAC may be influenced by molecular subtypes, further studies are needed to investigate the characteristics of residual carcinoma after NAC in patients with various molecular types of breast cancer. Third, for our predictive equation, a validation study is required before it can be formally used; therefore, additional studies are needed to evaluate its applicability.

\section{Conclusions}

In the present study, we investigated the characteristics of MRI and pathological shrinkage patterns and their relationship in patients with TNBC. We also developed a useful equation for estimating the size of residual cancer after NAC in patients with TNBC, based on the size noted on MRI. The newly developed equation may improve the success rates for BCS after NAC among patients with TNBC.

\section{Abbreviations}

BCS: Breast-conserving surgery; HER2: Human epidermal growth factor receptor 2; MRI: Magnetic resonance imaging; NAC: Neoadjuvant chemotherapy; pCR: Pathological complete responses; TNBC: Triple-negative breast cancer

\section{Acknowledgements}

Not applicable

\section{Authors' contributions}

$\mathrm{KY}$ analyzed and interpreted the patient data regarding the triple negative breast cancer after neoadjuvant chemotherapy. Ml and KY performed the histological examination of the breast and were major contributors in the writing of the manuscript. NK and KY reviewed the MRI findings. HY, KT, MS, and TS contributed to data interpretation. All authors read and approved the final manuscript.

\section{Funding}

This research did not receive any specific grant from funding agencies in the public, commercial, or not-for-profit sectors.

\section{Availability of data and materials}

The datasets used and/or analyzed during the current study are available from the corresponding author on reasonable request.

\section{Ethics approval and consent to participate}

All procedures performed in studies involving human participants were completed in accordance with the ethical standards of the institutional and/ or national research committee and with the 1964 declaration of Helsinki and its later amendments or comparable ethical standards. Informed consent: Informed consent was obtained from all individual participants included in the study.

\section{Consent for publication}

Not applicable.

\section{Competing interests}

The authors declare no conflict of interest.

\section{Author details}

${ }^{1}$ Department of Pathology and Clinical Laboratory, Kansai Medical University, 2-5-1, Shinmachi, Hirakata City, Osaka Prefecture 573-1010, Japan.

${ }^{2}$ Department of Surgery, Kansai Medical University, 2-5-1, Shinmachi, Hirakata City, Osaka Prefecture, Japan. ${ }^{3}$ Department of Radiology, Kansai Medical University, 2-5-1, Shinmachi, Hirakata City, Osaka Prefecture, Japan.

Received: 20 April 2020 Accepted: 15 July 2020

Published online: 21 July 2020

\section{References}

1. Cleator S, Heller W, Coombes RC. Triple-negative breast cancer: therapeutic options. Lancet Oncol. 2007;8:235-44.

2. Dent R, Trudeau M, Pritchard Kl, Hanna WM, Kahn HK, Sawka CA, et al. Triple-negative breast cancer: clinical features and patterns of recurrence. Clin Cancer Res. 2007;13:4429-34.

3. Foulkes WD, Smith IE, Reis-Filho JS. Triple-negative breast cancer. N Engl J Med. 2010;363:1938-48.

4. Fisher B, Brown A, Mamounas E, Wieand S, Robidoux A, Margolese RG, et al. Effect of preoperative chemotherapy on local-regional disease in women with operable breast cancer: findings from National Surgical Adjuvant Breast and Bowel Project B-18. J Clin Oncol. 1997;15:2483-93.

5. Fisher B, Bryant J, Wolmark N, Mamounas E, Brown A, Fisher ER, et al. Effect of preoperative chemotherapy on the outcome of women with operable breast cancer. J Clin Oncol. 1998;16:2672-85. 
6. Mamounas EP, Fisher B. Preoperative (neoadjuvant) chemotherapy in patients with breast cancer. Semin Oncol. 2001;28:389-99.

7. Goldhirsch A, Glick JH, Gelber RD, Coates AS, Senn HJ. Meeting highlights: International Consensus Panel on the Treatment of Primary Breast Cancer. Seventh International Conference on Adjuvant Therapy of Primary Breast Cancer. J Clin Oncol. 2001;19:3817-27.

8. Mauri D, Pavlidis N, loannidis JP. Neoadjuvant versus adjuvant systemic treatment in breast cancer: a meta-analysis. J Natl Cancer Inst. 2005;97:188-94.

9. Mieog JS, van der Hage JA, van de Velde CJ. Preoperative chemotherapy for women with operable breast cancer. Cochrane Database Syst Rev. 2007;2: CD005002.

10. Golshan M, Cirrincione CT, Sikov WM, Berry DA, Jasinski S, Weisberg TF, et al. Impact of neoadjuvant chemotherapy in stage II-III triple negative breast cancer on eligibility for breast-conserving surgery and breast conservation rates: surgical results from CALGB 40603 (Alliance). Ann Surg. 2015;262:434-9.

11. Akay CL, Meric-Bernstam F, Hunt KK, Grubbs EG, Bedrosian I, Tucker SL, et al. Evaluation of the MD Anderson Prognostic Index for local-regional recurrence after breast conserving therapy in patients receiving neoadjuvant chemotherapy. Ann Surg Oncol. 2012;19:901-7.

12. Marinovich ML, Houssami N, Macaskill P, Sardanelli F, Irwig L, Mamounas EP, et al. Meta-analysis of magnetic resonance imaging in detecting residual breast cancer after neoadjuvant therapy. J Natl Cancer Inst. 2013;105:321-33.

13. Chen JH, Bahri S, Mehta RS, Carpenter PM, McLaren CE, Chen WP, et al. Impact of factors affecting the residual tumor size diagnosed by MRI following neoadjuvant chemotherapy in comparison to pathology. J Surg Oncol. 2014;109:158-67.

14. Marinovich ML, Macaskill P, Irwig L, Sardanelli F, Mamounas E, von Minckwitz G, et al. Agreement between MRI and pathologic breast tumor size after neoadjuvant chemotherapy, and comparison with alternative tests: individual patient data meta-analysis. BMC Cancer. 2015;15:662.

15. Tomida K, Ishida M, Umeda T, Sakai S, Kawai Y, Mori T, et al. Magnetic resonance imaging shrinkage patterns following neoadjuvant chemotherapy for breast carcinomas with an emphasis on the radiopathological correlations. Mol Clin Oncol. 2014;2:783-8.

16. Kim TH, Kang DK, Yim H, Jung YS, Kim KS, Kang SY. Magnetic resonance imaging patterns of tumor regression after neoadjuvant chemotherapy in breast cancer patients: correlation with pathological response grading system based on tumor cellularity. J Comput Assist Tomogr. 2012;36:200-6.

17. Therasse P, Arbuck SG, Eisenhauer EA, Wanders J, Kaplan RS, Rubinstein L, et al. New guidelines to evaluate the response to treatment in solid tumors. European Organization for Research and Treatment of Cancer, National Cancer Institute of the United States, National Cancer Institute of Canada. J Natl Cancer Inst. 2000;92:205-16.

18. Ogston KN, Miller ID, Payne S, Hutcheon AW, Sarkar TK, Smith I, et al. A new histological grading system to assess response of breast cancers to primary chemotherapy: prognostic significance and survival. Breast. 2003;12:320-7.

19. Marinovich ML, Azizi L, Macaskill $P$, Irwig L, Morrow M, Solin LJ, et al. The association of surgical margins and local recurrence in women with ductal carcinoma in situ treated with breast-conserving therapy: a meta-analysis. Ann Surg Oncol. 2016;23:3811-21.

20. Brierley JD, Gospodarowicz MK, Wittekind C. TNM classification of malignant tumours. eighth ed. Singapore: Wiley-Blackwell; 2017.

21. Wu K, Yang Q, Liu Y, Wu A, Yang Z. Meta-analysis on the association between pathologic complete response and triple-negative breast cancer after neoadjuvant chemotherapy. World I Surg Oncol. 2014;12:95.

22. Liu Q, Wang C, Li P. The role of (18)F-FDG PET/CT and MRI in assessing pathological complete response to neoadjuvant chemotherapy in patients with breast cancer: a systematic review and meta-analysis. Biomed Res Int. 2016;2016:3746232

23. Nakahara H, Yasuda Y, Machida E, Maeda Y, Furusawa H, Komaki K, et al. MR and US imaging for breast cancer patients who underwent conservation surgery after neoadjuvant chemotherapy: comparison of triple negative breast cancer and other intrinsic subtypes. Breast Cancer. 2011:18:152-60.

24. Volders JH, Negenborn VL, Spronk PE, Krekel NMA, Schoonmade LJ, Meijer $S$, et al. Breast-conserving surgery following neoadjuvant therapy-a systematic review on surgical outcomes. Breast Cancer Res Treat. 2018;168: $1-12$

\section{Publisher's Note}

Springer Nature remains neutral with regard to jurisdictional claims in published maps and institutional affiliations.

\section{Ready to submit your research? Choose BMC and benefit from:}

- fast, convenient online submission

- thorough peer review by experienced researchers in your field

- rapid publication on acceptance

- support for research data, including large and complex data types

- gold Open Access which fosters wider collaboration and increased citations

- maximum visibility for your research: over $100 \mathrm{M}$ website views per year

At $\mathrm{BMC}$, research is always in progress.

Learn more biomedcentral.com/submissions 